\title{
Knowledge, Attitude and Practice of University Faculty Members and High School Teachers About Cervical Cancer Screening in Shiraz, Iran
}

\author{
Pegah Jahani ${ }^{1}$; Sulmaz Ghahramani ${ }^{2}$; Gholamreza Abdollahifard ${ }^{3, *}$ \\ ${ }^{1}$ Faculty of Medicine,Shiraz University of Medical Sciences,Shiraz,Iran \\ ${ }^{2}$ Health Policy Research Center, Shiraz University Of Medical Sciences, Shiraz, IR Iran \\ ${ }^{3}$ Department of Community Medicine, Shiraz University of Medical Sciences, Shiraz, IR Iran \\ ${ }^{*}$ Corresponding author: Gholamreza Abdollahifard, Department of Community Medicine, Shiraz University of Medical Sciences, Shiraz, IR Iran. Tel: +98-7112354431; +98-9177021196, \\ Fax:+98-7112359847, E-mail: rezagabdollahi@yahoo.com
}

Received: October 11, 2014; Accepted: April 20, 2015

\begin{abstract}
Background: Due to the increasing rate of cervical cancer screening, and the importance of teachers and faculties in changing the perspective of population on this issue, the present study was carried out to evaluate knowledge base, attitude and performance of teachers and faculty members in relation to cervical cancer screening test.

Objectives: This study attempted to evaluate the knowledge, attitude and performance of teachers and faculty members on cervical cancer screening test in Shiraz, Iran.

Patients and Methods: The present cross-sectional survey was conducted on a community with high education level. The study was carried out on a sample of 417 randomly selected subjects involving 206 participants from high school teachers and 211 faculty members. Stratified random sampling method was used proportionate to the size, of the main population in each group. Pvalue 0.05 was considered for estimating sample size. Valid and reliable questionnaires were completed via face to face interview. Data were analyzed using SPSS Software version 13.

Results: Mean score of knowledge (4.78 \pm 0.71$)$ was higher in faculty members than female teachers $(4.21 \pm 1.16)$. There was no statistically significant difference in mean scores of knowledge $(\mathrm{P}$ value $=0.748)$ and attitude $(\mathrm{P}$ value $=0.704)$ between teachers of different age groups. Mean score of knowledge (Pvalue $=0.001)$ and attitude $(\mathrm{P}$ value $=0.009)$ was significantly different among faculty members with different academic degrees. Although academics had higher Knowledge and attitude, the mean score of performance among teachers (18\%) was higher than faculty members (16.6\%).

Conclusions: This study showed that in regard to screening of cervical cancer, there is no acceptable knowledge, attitude and performance level among faculty members and teachers in different zones of Shiraz.
\end{abstract}

Keywords: Knowledge; Attitude; Practice; Cervical Cancer; Shiraz; Iran

\section{Background}

The etiology of Papiloma Virus (HPV) is the etiologic agent of cervical cancer and pre-invasive disease in human (1). HPV infection is the cause of Cervical Intraepithelial Neoplasia (CIN) and most common sexually transmitted diseases. Some types of HPV can cause genital warts (2). A study conducted in Southwest Nigeria show that risk of cervical cancer is higher among low socioeconomic women (3).

Worldwide, the third most common cancer is cervical cancer which caused 275,000 deaths in 2008. Most of the victims were in developing countries of which 159,800 cases were in Asia (4).

In Iran, cervical cancer is the $2^{\text {nd }}$ cause of cancer death after ovarian cancer (5). In 2006, Iran Cancer Institute report revealed that the prevalence rate of cervical cancer in Iran is estimated to be $6-7$ per 100,000. This report showed the growing rate of cervical cancer in recent years (6). Although most cases are from developing countries, they can be prevented due to the long pre-invasive period of the disease $(7,8)$. Screening for cervical cancer is crucial in decreasing the mortality and the incidence of this disease (9).

Moreover, recent studies reveal an effective vaccine against some types of HPV, which is not yet available (10). Pap smear, as a cheap and effective method, is one of the easiest and most acceptable ways of cervical cancer screening (11). Cervical cancer is a serious public health problem, leading to morbidity and mortality among women. Screening for cervical cancer has been improved over the past 50 years, (11) and as a result mortality and morbidity of cervical cancer has been reduced. In developed countries $40 \%$ - $50 \%$ of women screened for cervical cancer with Pap smear compared to 5\% in developing countries (7).

Cervical cancer screening program has not yet been practiced in most developing countries. Lack of resources and poverty are the most important impediments in cervical cancer screening in developing countries (10).

Copyright ( 2015 , Health Policy Research Center, Shiraz University of Medical Sciences. This is an open-access article distributed under the terms of the Creative Commons Attribution-NonCommercial 4.0 International License (http://creativecommons.org/licenses/by-nc/4.0/) which permits copy and redistribute the material just in noncommercial usages, provided the original work is properly cited. 
World Health Organization (WHO) guidelines reveal that programs for cervical cancer screening is limited in Iran (12). Teachers and faculty members could improve the knowledge of people they encounter with and could potentially change their attitude and behaviors toward cervical cancer screening.

\section{Objectives}

Therefore, in view of the importance of these groups in changing the perspective of population on this issue, and also the increasing rate of cervical cancer screening, the present study was carried out to evaluate the knowledge base, attitude and performance of teachers and faculty members in relation to cervical cancer screening test.

\section{Patients and Methods}

This survey was conducted in 2012 on a community with high education level. It is a cross-sectional study involving 206 participants from high school teachers from four educational regions and training organization and 211 faculty members of Shiraz University and Shiraz University of Medical Sciences, Shiraz, Iran.

The subjects under study were at least 40 years old and consented to participate in the study. Persons with histories of chronic diseases or any form of malignancies were excluded from the study. $P=50 \%$ and $\alpha=0.05$ were used for estimation of the sample size, which included 417 randomly selected patients and 206 participants from high school teachers and 211 faculty members, of whom 129 were from Shiraz University Of Medical Sciences and 82 from Shiraz University. Stratified random sampling method was used proportionate to the size of population in each group.

All academic staff were divided into 2 main groups of faculty members of Shiraz University and Shiraz University of Medical Sciences. Each university was then divided into different schools and sampling was done from each school depending on the number faculty members. Also the education and training organizations were then divided into four regions, each of which, were divided into four subject groups of mathematics, experimental, humanities and technical fields. Questionnaires were completed via face to face interview. Kruskal Wallis test was used to compare the score of knowledge, attitude and performance between teachers and faculties. Validity and internal consistency were checked by the research team and assessed by applying a Chronbach's alpha test with minimal $\alpha=0.72$. Participation in the study was completely voluntary.

The questionnaire designed included 3 parts; 18 questions (18 scores) assigned to women and 24 (24 scores) to men. The questionnaire evaluated the attitude, knowledge and performance of participants. Attitude was evaluated by perspective of individuals about screening. Also, the age at first screening test was considered as a fac- tor which demonstrated the knowledge. The evaluation of performance was based on whether they had done screening test during their lifetime.

The data were analyzed using SPSS software version 13 . The participants were classified into 3 groups of ideal, acceptable and poor, according to the scores obtained. With respect to knowledge and attitude about screening, the scores more than $65 \%$ of the total score were sufficient, acceptable represented 35\% to $64.9 \%$ and less than $35 \%$ were rated as poor.

\subsection{Statistical Analysis}

Descriptive and analytic methods were used for data analysis. Mean and Standard Deviation (SD) were used to provide descriptive information about the participants. Due to the non-normal distribution of scores of knowledge, attitude and practice, Kruskal Wallis test was applied.

\section{Results}

Mean score of knowledge ( $4.78 \pm 0.71)$ of female faculty members was more than mean score of knowledge (4.21 $\pm 1.16)$ of female teachers. There was no significant difference between Knowledge $(P=0.198)$ and attitude $(P=$ 0.391) of teachers with different educational degree.

There was no significant difference in mean score of knowledge $(P=0.204)$ and attitude $(P=0.759)$ between teachers in different fields. Mean scores of knowledge and attitude in teachers of different fields and faculty members toward cervical cancer screening are shown in Table 1.

There was no significant difference in mean scores for attitude $(\mathrm{P}=0.128)$ towards cervical cancer screening among school teachers in different distinctions, but in regard to the mean score for knowledge the difference was significant $(P=0.001)$. The difference in mean scores of knowledge $(\mathrm{P}=0.748)$ and attitude $(\mathrm{P}=0.704)$ in teachers of different age groups was not statistically significant. Mean scores of knowledge and attitude of teachers and faculty members of different age groups toward cervical cancer screening are demonstrated in Table 2.

Mean scores of knowledge $(\mathrm{P}=0.003)$ and attitude $(\mathrm{P}=$ 0.040) of faculty members of Shiraz University of Medical Sciences and Shiraz University regarding prostate cancer screening differed significantly. Mean scores of knowledge and attitude regarding cervical cancer screening among faculty members with different academic degrees are shown in Table 3.

There was statistically significant difference in mean scores of knowledge $(P=0.002)$ and attitude $(P=0.001)$ among faculty members in different fields. Mean score of knowledge of faculty members in different fields was significantly different where engineering had the highest mean score $(4.96 \pm 0.18)$ and Basic medicine had the least mean score ( $4.53 \pm 0.72)$. Mean score of attitude of faculty members in different fields was significantly different, in which human sciences had the least $(2.86 \pm 1.02)$ and 
Jahani Pet al.

Table 1. Mean Scores of Knowledge and Attitude of Faculty Members in Different Fields and Teachers Toward Cervical Cancer Screening ${ }^{\mathrm{a}}$

\begin{tabular}{|c|c|c|c|c|c|}
\hline \multirow[t]{2}{*}{ Field } & \multicolumn{2}{|c|}{ Academics } & \multirow[t]{2}{*}{ Field } & \multicolumn{2}{|c|}{ Teachers } \\
\hline & Knowledge & Attitude & & Knowledge & Attitude \\
\hline Human sciences & $4.86 \pm 0.74$ & $2.86 \pm 1.02$ & Human sciences & $4.31 \pm 1.12$ & $4.81 \pm 1.50$ \\
\hline Engineering & $4.96 \pm 0.18$ & $3.66 \pm 0.88$ & Natural sciences & $4.14 \pm 1.19$ & $4.95 \pm 1.39$ \\
\hline Health science & $4.92 \pm 0.26$ & $4.35 \pm 0.63$ & Mathematic & $4.00 \pm 1.27$ & $4.73 \pm 1.48$ \\
\hline Basic medicine & $4.53 \pm 0.72$ & $3.93 \pm 1.31$ & Technical sciences & $3.00 \pm 1.00$ & $4.66 \pm 1.52$ \\
\hline Clinical medicine & $4.72 \pm 0.83$ & $3.96 \pm 0.86$ & Total & $4.21 \pm 1.16$ & $4.8 \pm 1.47$ \\
\hline Total & $4.78 \pm 0.71$ & $3.67 \pm 1.06$ & Pvalue & 0.204 & 0.759 \\
\hline P value & 0.002 & 0.001 & & & \\
\hline
\end{tabular}

a Values are presented as Mean \pm SD.

Table 2. Mean Scores of Knowledge and Attitude of Teachers and Faculty Members in Different Age Group Toward Cervical Cancer Screening ${ }^{\text {a }}$

\begin{tabular}{|c|c|c|c|c|}
\hline \multirow[t]{2}{*}{ Age, y } & \multicolumn{2}{|c|}{ Faculty Members } & \multicolumn{2}{|c|}{ Teachers } \\
\hline & Knowledge & Attitude & Knowledge & Attitude \\
\hline $40-44$ & $4.85 \pm 0.48$ & $3.78 \pm 1.01$ & $4.22 \pm 1.09$ & $4.68 \pm 1.36$ \\
\hline $45-49$ & $4.67 \pm 0.93$ & $3.55 \pm 1.06$ & $4.14 \pm 1.29$ & $4.88 \pm 1.56$ \\
\hline 50 & & & $4.36 \pm 1.01$ & $4.86 \pm 1.51$ \\
\hline $50-54$ & $4.88 \pm 0.46$ & $3.69 \pm 1.20$ & & \\
\hline 55 & $4.61 \pm 1.06$ & $3.55 \pm 1.06$ & & \\
\hline
\end{tabular}

a Values are presented as Mean \pm SD.

Table 3. The Mean Scores of Knowledge and Attitude Regarding Cervical Cancer Screening in Faculty Members With Different Academic Ranks

\begin{tabular}{lcc}
\hline Academic Rank & Knowledge & Attitude \\
\hline Mentor & $3.96 \pm 1.08$ & $3.67 \pm 1.47$ \\
\hline Assistant & $4.64 \pm 0.60$ & $3.70 \pm 1.04$ \\
\hline Associate & $4.85 \pm 0.48$ & $4.12 \pm 0.79$ \\
Professors & $4.95 \pm 0.24$ & $1.96 \pm 0.31$ \\
Total & $7.78 \pm 0.71$ & $3.67 \pm 1.07$ \\
P value & 0.001 & 0.009 \\
\hline
\end{tabular}

health sciences had the highest mean score $(4.35 \pm 0.63)$. Mean scores of knowledge $(\mathrm{P}=0.001)$ and attitude $(\mathrm{P}=$ 0.009 ) were significantly different among faculty members with different academic degrees, with associate professors having the highest mean score of attitude (4.12 $\pm 0.79)$. Although professors had the highest mean score of knowledge $(4.95 \pm 0.24)$ toward cervical cancer screening, they had the least mean score of attitude $(3.5 \pm 1.03)$. Instructors had the least mean score of knowledge (3.96 $\pm 1.08)$. Mean scores of knowledge $(P=0.333)$ and attitude $(\mathrm{P}=0.600)$ between faculty members of different age groups were not statistically significant.

The mean score of performance among teachers (18\%) was higher than academics (16.6\%). The mean score of academic staff of Shiraz University (13.4\%) was less than those of Shiraz University of Medical Sciences (18.6\%).

There were no statistically significant differences between the mean scores of performance of teachers in different age groups. Moreover, there were no statistically significant differences between mean scores of performance of teachers with different academic degrees.

In regard to performance, there were significant differences between mean scores of faculty members with different academic ranks $(P=0.013$, with instructors having the highest performance (38.5\%). Moreover, there was a significant difference between the mean score of academics in different fields $(P=0.026)$. The academics in field of engineering had the highest performance (26.7\%), and academics in the field of human sciences had the lowest mean score. There was no statistically significant difference between the mean scores of performance among faculty members in different age groups.

\section{Discussion}

Cervical cancer is a preventable disease and one of the most important tools of prevention is increasing public awareness. In view of increasing rate of cervical cancer, the results of this study highlighted lack of knowledge, attitude and performance among teachers and academics, which were consistent with the report of another study conducted in Qatar (7).

Another reason for deficient knowledge among most 
women about cervical cancer screening is that they get their information from people with whom they communicate, such as relatives and friends, rather than physicians or social media. This can be attributed to the absence of a well-organized cervical cancer screening program (7).

Lack of adequate knowledge and embarrassment maybe impediment to patients' reluctance to perform cervical cancer screening (6). In our study we found that mean score of knowledge and attitude of academics toward cervical cancer screening was higher than teachers but mean score of performance of teachers was higher than faculty members; this is possibly due to teachers having more time to do screening than academics.

There was no statistically significant difference in mean score of knowledge between different age groups, a finding consistent with and contrary to the results of different studies $(7,13)$. In our study the highest mean score of knowledge was found among teachers aged more than 50 years ( $4.36 \pm 1.01)$, which was not in agreement with the results of another study, possibly due to the fear of cancer and death.

As for the mean score of attitude, there was no statistically significant difference between various age groups, which was similar to the results of another study (14).

The mean score of performance of instructors was highest among all academic staff, which may be due to instructors having more free time to refer to physicians, than other academics. It has been shown that recommendations for cervical cancer screening to individuals by medical professionals could considerably improve screening coverage among the general population (9).

The engineering academics had the highest mean score of performance (26\%), which may be due to having more free time, whereby they can obtain information about cervical cancer and screening program through electronic media.

The limitation of this study was that the evaluation of teachers and academics' knowledge, attitude and performance about cervical cancer screening, could not be generalized to include other groups of people in different locations. Also self-reporting may have biased the process of data collection. Furthermore, the prevalence of cervical cancer in these areas may be affected by the socioeconomic status of the participants.

Physicians' recommendations for cervical cancer screening play an important role in improving the performance and attitude of patients. The results of this study showed that there is no acceptable knowledge, attitude and performance toward cervical cancer screening. Because of the increasing rate of cervical cancer in Iran, it is necessary to introduce programs to increase knowledge and improve attitude and performance of the population about cervical cancer. This is a policy which highlights the importance of the ever increasing need for planning for cervical cancer screening. The social media, health professionals, and other related sources can provide the necessary information about cervical cancer screening and the importance of detecting the cancer in the early stage. Decreasing working hours of faculty members would help them devote some of their free time to health programs. The implementation of free or low cost screening programs can increase the performance of population.

The provision of leaflets about the symptoms, risk factors of cervical cancer, method of screening, high risk groups and effectiveness of screening in reducing the mortality can improve knowledge, attitude and performance of people.

\section{Acknowledgements}

This article was extracted from the thesis prepared by Ali Ghaleb to fulfill the requirements for earning the Medical doctor degree. This work is supported by the vice chancellor of research at Shiraz University of Medical Sciences.

\section{Authors' Contributions}

Study concept and design: Gholamreza Abdollahifard. Acquisition of data: Pegah Jahani. Analysis and interpretation of data: Gholamreza Abdollahifard, Sulmaz Ghahramani, Pegah Jahani. Drafting of the manuscript: Sulmaz Ghahramani, Pegah Jahani. Critical revision of the manuscript for important intellectual content: Gholamreza Abdollahifard. Statistical analysis: Sulmaz Ghahramani, Administrative, technical, and material support: Gholamreza Abdollahifard. Study supervision: Gholamreza Abdollahifard, Sulmaz Ghahramani.

\section{Funding/Support}

This work is supported by the vice chancellor of research at Shiraz University of Medical Sciences.

\section{References}

1. Hanisch R, Gustat J, Hagensee ME, Baena A, Salazar JE, Castro MV et al. Knowledge of Pap screening and human papillomavirus among women attending clinics in Medellin, Colombia. Int J Gynecol Cancer. 2008;18(5):1020-6.

2. Gannon M, Dowling M. Increasing the uptake of cervical screening programmes. BrJ Nurs. 2008;17(20):1280-4.

3. Adekanle DA, Adeyemi AS, Afolabi AF. Knowledge, Attitude and Cervical Cancer Screening Among Female Secondary School Teachers in Osogbo, Southwest Nigeria. Academic J of Cancer Res. 2011;4:24-8.

4. Sait KH. Knowledge, attitudes, and practices regarding cervical cancer screening among physicians in the Western Region of Saudi Arabia. Saudi Med J. 2011;32(11):1155-60.

5. Karimi Zarchi M, Akhavan A, Fallahzadeh H, Gholami H, Dehghani A, Teimoori S. Outcome of cervical cancer in Iranian patients according to tumor histology, stage of disease and therapy. Asian Pac J Cancer Prev. 2010;11(5):1289-91.

6. Akbari F, Shakibazadeh E, Pourreza A, Tavafian SS. Barriers and Facilitating Factors for Cervical Cancer Screening: a Qualitative Study from Iran. Iran J of Cancer Prevention. 2010;3(4).

7. Al-Meer FM, Aseel MT, Al-Khalaf J, Al-Kuwari MG, Ismail MF. Knowledge, attitude and practices regarding cervical cancer and 


\section{Jahani Pet al.}

screening among women visiting primary health care in Qatar. East Mediterr Health J. 2011;17(11):855-61.

8. Rezaie-Chamani S, Mohammad-Alizadeh-Charandabi S, Kamalifard M. Knowledge, Attitudes and Practice about Pap Smear among Women Reffering to A Public Hospital.Journal of Family 8 Reproductive Health. 2012;6(4).

9. Yoshino Y, Ohta H, Kawashima M, Wada K, Shimizu M, Sakaguchi $\mathrm{H}$, et al. The knowledge of cervical cancer and screening adherence among nurses at a university-affiliated hospital in Japan. Age. 2012;20(29):280.

10. Goldie SJ, Gaffikin L, Goldhaber-Fiebert JD, Gordillo-Tobar A, Levin $\mathrm{C}$, Mahe $\mathrm{C}$, et al. Cost-effectiveness of cervical-cancer screening in five developing countries. N Engl J Med. 2005;353(20):2158-68.

11. Nokiani FA, Akbari H, Rezaei M, Madani H, Ale Agha ME. Cost-effectiveness of pap smear in Kermanshah, Iran. Asian Pac J Cancer Prev. 2008;9(1):107-10.

12. Kolahdoozan S, Sadjadi A, Radmard AR, Khademi H. Five common cancers in Iran. Arch Iran Med. 2010;13(2):143-6.

13. Amarin ZO, Badria LF, Obeidat BR. Attitudes and beliefs about cervical smear testing in ever-married Jordanian women. East Mediterr Health J. 2008;14(2):389-97.

14. Nakandi H, Kirabo M, Semugabo C, Kittengo A, Kitayimbwa P, Kalungi S, et al. Knowledge, attitudes and practices of Ugandan men regarding prostate cancer. Afr J Urol. 2013;19(4):165-70. 